\title{
La otra cara del idilio alpino: el exilio de Else Lasker-Schüler en Suiza ${ }^{1}$
}

\author{
Isabel HERNÁNDEZ \\ Departamento de Filología Alemana \\ Universidad Complutense de Madrid \\ isabelhg@filol.ucm.es
}

\begin{abstract}
RESUMEN
La idea generalizada de Suiza como país de acogida de intelectuales exiliados en diferentes periodos del siglo XX no se corresponde a menudo con la realidad. Elegido como destino de emigración preferente para muchas mujeres ya desde la segunda mitad del siglo XVI, durante las guerras de religión en Francia, Suiza continuó siendo durante los siglos posteriores, y, sobre todo, durante el siglo XX, lugar preferente en el que encontrar refugio para muchos intelectuales. En el caso de las mujeres, no obstante, las dificultades con las que éstas se encontraron no fueron pocas, pues nunca llegaron a perder su condición de exiliadas, al tiempo que tuvieron que enfrentarse a un entorno laboral dominado casi exclusivamente por hombres. El presente trabajo pretende poner de manifiesto la realidad del periodo de exilio en Suiza tomando como ejemplo el caso significativo de Else Lasker-Schüler.
\end{abstract}

Palabras clave: exilio, desarraigo, expatriación, Suiza, Lasker-Schüler.

The dark side of the Alpine Idyll: Else Lasker-Schüler's exile in Switzerland

\begin{abstract}
The widespread image of Switzerland as a welcoming land for exiles during the 20th Century does not always correspond to reality. Often the destination of choice for many women from the $1550 \mathrm{~s}$, who at that time felt the urge to abandon France due to religious wars, Switzerland remained a safe haven for numerous intellectuals in the following centuries, and most particularly in the 20th Century. Nonetheless, women were compelled to face numerous obstacles in their Swiss asylum: besides never losing their status as exiles, they had to struggle to find a place of their own in a male-dominated professional environment. This paper aims to illustrate the reality of Swiss exiles with the significant example of Else Lasker-Schüler.
\end{abstract}

Key words: exile, displacement, expatriation, Switzerland, Lasker-Schüler.

\footnotetext{
1 Este trabajo se inserta dentro del proyecto de investigación FEM2009-09506 "Judaísmo y feminidad: representaciones del género y de la cultura en conflicto en la literatura alemana moderna y contemporánea" financiado por el Ministerio de Educación y Ciencia.
} 
¿Vivimos en el siglo de la literatura del exilio? La Revolución Rusa, la Guerra Civil Española, el Tercer Reich han empujado a miles de intelectuales al exilio, y el número de autores que a día de hoy tienen que abandonar su hogar por motivos políticos sigue aumentando. Se mire a donde se mire: Sudamérica, Asia, África, Europa, cada uno de estos continentes "produce" diariamente nuevos exilados, a menudo bajo presupuestos políticos contrarios.

Karl Corino, Autoren im Exil (1981)

La conocida tradición humanitaria de Suiza como país de acogida para todo tipo de perseguidos políticos o de cualquier otra condición constituye a día de hoy una parte importante de la identidad de la nación suiza. Esta tradición es larga y variada, pero no por ello ha dejado de mostrar toda una serie de fracturas a lo largo del tiempo. De ella hay ya claros indicios desde el mismo momento de la fundación de la moderna Confederación: Ulrich von Hutten, Jean Calvin y los hugonotes durante los siglos XVI y XVII, Heinrich von Kleist y Jean-Jacques Rousseau en el XVIII, Lord Byron y Georg Büchner en la primera mitad del XIX, todos ellos y muchos otros sin nombre conocido se asentaron en Suiza tratando de escapar de situaciones de opresión bien diferenciadas. Después, tras su fundación a mediados del siglo XIX, la Suiza moderna continuó manteniendo su arraigada tradición de asilo, proporcionando amparo y seguridad a muchos individuos en diferentes situaciones de necesidad. Pero fue sobre todo a lo largo del siglo pasado cuando el país, dada la situación reinante en Europa, habría de convertirse en un refugio seguro para perseguidos; sin embargo, a pesar de su tradición, durante el terrible periodo del nacionalsocialismo, Suiza actuó de forma inesperada, negando su ayuda a miles de personas, para las cuales no entrar en el país suponía una muerte segura. ¿Es, por tanto, esta faceta tan reconocida y apreciada de Suiza como país de acogida un mito o una realidad ${ }^{2}$ ?

Nacida en 1869 en Elberfeld, en las cercanías de Wuppertal, en Westfalia, en el seno de una familia judía de la burguesía asimilada, Else Lasker-Schüler (18691945) se convirtió pronto en una de las escritoras más reconocidas por los medios artísticos de Berlín, y en una de las representantes de un mundo cultural que muy pronto vendría a destruir el nacionalsocialismo. A partir de entonces su vida se convertiría en un continuo ir y venir de marido en marido, de amigo en amigo, de personaje literario en personaje literario, de ciudad en ciudad y de país en país. Marginada en Alemania y exiliada en Suiza y Palestina, su obra está claramente marcada

\footnotetext{
2 En este sentido son muy interesantes las reflexiones del profesor Peter von Matt: "Nací en 1937. Durante toda mi infancia, hasta mis primeros años de escuela, se estuvo rechazando a miles de personas en la frontera, mandando a muchas de ellas a una muerte segura. Esto se hacía abiertamente en interés de los suizos y suizas, es decir, también de mi persona. Suiza no debía superpoblarse, mezclarse con grupos de gente indeseada, llenarse de bocas hambrientas que se comieran el pan de cada día de los suizos y las suizas, es decir también el mío. Jamás pasé hambre en mi infancia. Se lo agradezco, entre otras cosas, a la injusticia de este Estado. Si hoy reconozco una culpa en la práctica concreta de esa injusticia, reconozco también que tengo parte en ella. Yo me beneficié de ello. Es un hecho que no puedo separar de mi vida" (Von Matt 2003: 7).
} 
por este continuo andar errante inherente al exiliado, a quien se ha quedado sin patria. A ello, además, se unen en el caso de Else tres acontecimientos de carácter claramente personal que convirtieron su producción literaria en una de las más singulares de todo ese periodo: la muerte de su hermano favorito Paul, en 1882; la de su propio hijo, nacido en 1899 de padre desconocido y al que llamará Paul en recuerdo de su hermano, y la de su madre en 1890.

En el caso de esta poetisa, son los hechos condicionantes de su biografía, por tanto, los que llenan toda su obra, ya sea lírica, narrativa o dramática, de motivos como la huida, la expulsión, la nostalgia, la pérdida, la muerte y la partida. El exilio y Else Lasker-Schüler están, ya desde muy pronto, intrínsecamente relacionados y ofrecen múltiples e interesantes perspectivas para la investigación, sobre todo por los aspectos a día de hoy aún poco conocidos de algunos de los acontecimientos que vivió en los diversos lugares por los que fue pasando en su continuo andar errante.

Fue en 1918 cuando Else Lasker-Schüler pasó por vez primera una temporada en Suiza. Fueron tan sólo cuatro meses: del 4 de enero al 20 de marzo y del 29 de abril al 16 de mayo, en los que residió en las localidades de Zúrich y Locarno. Tras otra estancia posterior en Zúrich en julio de 1918, Else regresó a Berlín donde permaneció hasta que en 1933 decidió escapar de la Alemania nazi. Fue el artista Peter Hille, uno de sus mejores amigos, el primero que le habló de las bondades de la Confederación, impresionado por las virtudes del país, tras haber recorrido durante largo tiempo otros muchos como Holanda, Inglaterra o Italia. De ahí que no resulte extraño que sea precisamente durante el periodo de la I Guerra Mundial, cuando Else visite Suiza por primera vez, al igual que otros muchos intelectuales llegados allí de los rincones más diversos de la geografía europea. Puesto que por esas fechas era ya una poetisa reconocida a nivel internacional, Else pudo participar rápidamente de la vida intelectual del país y moverse en el triángulo cultural constituido en la ciudad de Zúrich por el Schauspielhaus, el Café Odeon en Bellevue y el Cabaret Voltaire en la Spielgasse. En este último tuvo ocasión de ver representaciones dadaístas en las que intervinieron como actores principales autores de la talla de Tristan Tzara, Hans Arp, Sophie Täuber-Arp y Hugo Ball. Todos ellos, en 1917, habían declarado Suiza como "la gran reserva natural" en la que el resto de las naciones podían conservar y asegurar sus últimas reservas literarias, refiriéndose con ello, evidentemente, a composiciones del momento, a la obra de autores no demasiado bien vistos, como era el caso de Karl Kraus, Hugo von Hofmannsthal, Carl Sternheim, Stefan Zweig, Franz Werfel y la propia Lasker-Schüler. Es normal, pues, que Else se sintiera en Zúrich bien acogida y disfrutara sobremanera de tal entorno. Es precisamente así como la describe Claire Goll en sus memorias:

A un lado veo a Else Lasker-Schüler, radiante, halagada, la reina de Berlín. La reconocían por la calle y nadie ponía en duda su superioridad poética. Dominaba a sus admiradores y disfrutaba de su fama con una despreocupada arrogancia. Una mirada suya abría todas las puertas, con una sonrisa cumplía todos los deseos... Era la heroína de toda una generación y cada una de sus publicaciones expandía su fama más y más. (Goll 1999: 6) 
En marzo de 1918, Else tiene por primera vez la posibilidad de leer sus poemas ante el prestigioso círculo literario de Zúrich-Hottingen, denominado así porque había establecido su sede en este barrio de las afueras de la ciudad, y comienza a publicar una serie de poemas en las Weisse Blätter, dirigidas entonces por René Schickele; otros muchos aparecen también en diversas antologías y no pasa desapercibida en el Café de la Terrasse, donde un testigo la describe de la siguiente manera:

Muchas veces encontrábamos a Else Lasker-Schüler en el Café de la Terrasse, rodeada de una corte de admiradores, jugando con unos caramelos. Siempre llevaba algunos encima [...]. Incluso pagaba con esos dulces, y los camareros le seguían el juego, pues su fama de excéntrica se había extendido ya hasta el último de ellos. Le perdonaban todo. Por aquel entonces era la gran poetisa alemana y nadie se atrevía a negarle nada. (Goll 1999: 38)

Los meses que Else pasó en Suiza fueron para ella enormemente positivos y, sin duda, contribuyeron de manera decisiva a que la autora se forjase una idea idílica del país alpino, que había quedado completamente al margen del conflicto bélico y sus terribles consecuencias, que más tarde ella misma comprobaría como falseada, pues no coincidía en absoluto con la realidad. Poco tiempo después, Else habría de experimentar en su propia persona cómo los suizos no eran los individuos solidarios que ella creía, y que el pueblo helvético en absoluto hacía honor a las características con que tan positiva y bondadosamente lo había descrito Friedrich Schiller en su Guillermo Tell. El origen de este cambio de actitud tan radical puede hallarse tal vez en el hecho de que, coincidiendo con el final de la I Guerra Mundial, tuvo lugar en Suiza una hambruna terrible que, unida a una epidemia de gripe, causó una elevada mortandad en el país alpino. Como consecuencia de ello, se acentuaron drásticamente las diferencias entre el campo y la ciudad y, en noviembre de 1918, se declaró el estado de huelga general que llevó a que el ejército tuviera que intervenir directamente contra los huelguistas. La Confederación se hallaba en ese momento al borde del colapso, es más, incluso de una guerra civil y de una revolución social como no había conocido nunca hasta entonces. La burguesía estaba convencida de que todos estos problemas internos habían sido causados por los primeros inmigrantes llegados al país, esto es, por los revolucionarios rusos que habían llevado consigo su ideología para tratar de imponerla en la pacífica Suiza. Ello llevó a que la Confederación experimentara un giro radical hacia la derecha, que tuvo como consecuencia, al margen de la política de neutralidad, la ruptura de relaciones diplomáticas con la joven Unión Soviética, que no serían restablecidas hasta 1946.

Vista la situación, la fiscalía de Berna decidió no dar asilo político a ningún perseguido procedente de países socialistas y comunistas, e incluso prohibirles la entrada en Suiza. Entre los afectados se encontraban escritores y pensadores de la talla de Georg Lukàcs, Erich Mühsam o Ernst Toller. Pero también la propia Else LaskerSchüler, que, más allá de la temática integradora que describía en su obra, no demostró tener una ideología política concreta. Durante ese periodo de tiempo, Else evitó Suiza y residió en Berlín junto con su hijo, que pronto enfermaría de tuberculosis, 
pero, aunque ella siempre consideró esta ciudad como su lugar de residencia, Suiza no dejó nunca de estar en sus pensamientos y, por ello, mantuvo vivo en todo momento el contacto con el país a través de los amigos y conocidos que allí residían. En 1923 pudo, por fin, regresar para pasar una temporada en el Tesino con unos amigos. Durante esta visita tuvo también ocasión de pronunciar una conferencia invitada por Eduard Korrodi, el director del suplemento cultural del Neue Zürcher Zeitung, diario en el que comenzó a publicar regularmente poemas y textos breves en prosa a partir de 1925 .

A principios de 1927, el año en que falleció su hijo, Else volvió a detenerse en Zúrich en uno de los muchos viajes que ese año realizó a Berlín. Su afinidad con esta ciudad aparece claramente puesta de manifiesto en una carta escrita a Korrodi:

Las gaviotas del lago de Zúrich me escriben cartas tan nostálgicas, y yo desearía estar viendo esas blancas aves, esa nieve que grita, esas novias silvestres del mar del Norte, esas aventureras de suaves plumas [...]. Ya ve, doctor, que mis pensamientos están en Zúrich; me encuentro en su amplia estación de ferrocarril y percibo con encanto con cuánta amabilidad se encuentran unas con otras todas las lenguas del mundo, y entonces creo que sólo es posible educar a personas tolerantes y con tacto dejando que todas se mezclen entre sí sin impedirlo. (Kosch 2002: 126)

Una admiración que llegó incluso a plasmarse en frases como esta declaración de amor: "Amo Suiza, mucho más allá de esta interesante Bahnhofstrasse de Zúrich, que lleva hasta los cafés, el de la Terrase y el Odeon” (Kosch 2002: 126).

La admiración era, por cierto, compartida con otros muchos intelectuales de la época, pero es perfectamente comprensible que una escritora como Else LaskerSchüler, que entre 1918 y 1933 residió en Suiza en tantas ocasiones, en lugares tan diferentes como el Tesino, Davos y Zúrich, creyera encontrar en el país la utopía soñada, y con ella prácticamente todos los motivos y temas que, posteriormente, aparecerían reflejados en el conjunto de su obra literaria, como el de la coexistencia pacífica de diferentes pueblos, lenguas y etnias, que la recorre de principio a fin como una espina dorsal.

En abril de 1933 Else Lasker-Schüler regresa de nuevo a Suiza, pues ya no se siente segura en Berlín. Allí deja atrás sesenta y cuatro años de su vida, pasada en una Alemania que ama por su cultura y odia por su hostilidad, pero que, aun sin expresarlo manifiestamente, espera volver a encontrar algún día. Sin embargo, el exilio interior que llevaba ya años viviendo, y al que había llegado forzada por un entorno cotidiano en el que las personas que la rodeaban no le permitían vivir según sus convicciones, obligándola a cortar toda comunicación con ellos y a retirarse a su mundo imaginario, en el que nadie se atrevía a atacarla ${ }^{3}$, se transforma ahora en un

\footnotetext{
3 Una de las características que definen la obra de Else Lasker-Schüler es precisamente la de la creación de un mundo, de un lenguaje y de unos personajes imaginarios, tras los que la autora se refugia en todo momento. Lo primero es general para toda su obra, para toda su utopía literaria, lo segundo predomina, evidentemente, en la lírica, y lo último en la prosa. Aquí, Else, imbuida por el mundo oriental, construye una serie de personajes, entre los que destaca el príncipe Yussuf, encarnación de sí misma, y a través del que trata de personificar la simbiosis de religiones y culturas en la que siempre creyó.
} 
exilio concreto dentro de un espacio geográfico concreto: Suiza. Antes de partir, Else envía una carta casi codificada a Klaus Gebhard, dueño de una fábrica textil, explicándole que tiene la intención de llevar a cabo una serie de lecturas públicas de su obra en diferentes localidades suizas. Lo que busca, en realidad, es apoyo económico, pero también social, pues la huida de Alemania la confronta una vez más con una realidad de la que comienza a dudar profundamente, una realidad que le ha privado de toda ilusión respecto del mundo y que le hace revivir asimismo otro de sus grandes deseos existenciales: el de su relación con el pueblo judío.

Pero Else llega a Suiza también con la esperanza de que se estrene su obra Arthur Aronymus. Die Geschichte meines Vaters (Arthur Aronymus. La historia de mi padre) en el Schauspielhaus de Zúrich ${ }^{4}$, cosa que no ve demasiado difícil puesto que ese mismo año se le ha concedido el Premio Heinrich von Kleist por su obra completa $^{5}$, aumentando con ello su prestigio como escritora a nivel internacional. Esta obra, dedicada a la memoria de su padre, es también uno de sus textos más idealistas, tal vez aquel en el que la reconciliación entre las diferentes religiones y, por tanto, la temática de la coexistencia pacífica entre judíos y alemanes tiene un peso mayor. Es en ella, por tanto, donde con más claridad se deja ver el mencionado ideal de la simbiosis judeoalemana que guió como un leitmotiv toda su producción ${ }^{6}$. Lo que Else no podía imaginar al abandonar Berlín con estos proyectos e ideas en su mente era que no volvería a ver Alemania jamás.

Pero tampoco sabía qué le depararía su estancia en Suiza. Durante los años 30 el país helvético se vio dominado, aún más que en la década anterior, por una xenofobia generalizada, no conocida hasta entonces. Con todo, y a pesar del tiempo transcurrido, no es mucho lo que se sabe de las medidas tomadas por el gobierno y por el ejército en aquellos años, dirigidas sobre todo a la prohibición de publicar en prensa escritos de orientación izquierdista, así como todo tipo de obras literarias de características similares. Esta prohibición alcanzó también a la representación de obras en los teatros y de películas en los cines. El periodo comprendido entre 1933 y 1945 supuso, por tanto, una prueba de fuego para todos los escritores que residían en la Confederación, pues ni la denominada política de Defensa del Espíritu Nacional ni las campañas difamatorias que tuvieron lugar una vez concluido el conflicto contribuyeron a una relación directa entre los escritores suizos y los exiliados,

4 La obra se estrenó el 19 de diciembre de 1936; se trata de una saga familiar en la que se da testimonio de la simbiosis judeoalemana en el siglo XIX. Los críticos aplicaron, curiosamente, criterios propios de la defensa del espíritu nacional a una obra de tales características, dando como resultado unos textos con rasgos enormemente positivos.

5 Seguramente debido al año en que se le concede el premio, Else hubo de compartirlo con un escritor nacionalista, Richard Billinger. Tres días antes de la nominación de Else el periódico Völkischer Beobachter, el diario oficial del NSDAP, el partido nacionalsocialista, había expresado abiertamente su repulsa ante tal designación.

6 En este sentido debe mencionarse el hecho de que Else contrajo matrimonio en dos ocasiones. La primera con Berthold Lasker, un médico que le da clases de dibujo y le alquila un estudio en Berlín; la segunda con Georg Levin, al que ella llamaba Herwarth Walden. Levin, a pesar de su radicalismo, fue siempre un judío asimilado que trataba de hacerse un sitio en la sociedad. Los dos la decepcionaron enormemente, pues renunciaron a la esencia de la cultura judía. El judío asimilado jamás aparece en sus textos como un ejemplo de acercamiento entre las diferentes comunidades religiosas. Sólo el judío orgulloso de su judaísmo y de la tradición merece su respeto. De ahí que califique siempre a los primeros de filisteos. 
dado que fueron muy pocos los autores helvéticos que, durante ese periodo, se sintieron capaces de sustraerse a los dictados de semejante política conservadora.

$Y$ es que en Suiza reinaba por aquel entonces una atmósfera de crisis y de estrechez de miras, debida precisamente al triunfo de esta nueva ideología con la que Suiza se defendía ante un claro peligro de "Überfremdung", es decir, de una afluencia masiva de extranjeros, que podría conllevar la pérdida de la propia identidad. Escritores, actores, pintores e intelectuales de todo tipo orientaron, pues, su trabajo en función de una búsqueda de la identidad nacional, con lo cual se evitó de principio a fin todo contacto con aquello que viniera de fuera o que supusiera también una competencia externa. En lo referente a la literatura, esta actividad de distanciamiento de todo lo extranjero es llevada a cabo fundamentalmente por la Asociación de Escritores, la cual, con los informes que redactaba por encargo de la policía de inmigración, ayudaba a las autoridades a decidir sobre la concesión o la denegación de los permisos solicitados. Ya en 1933 se habían fijado las siguientes directrices para enjuiciar la calidad literaria de los autores en el exilio:

Se permitirá la residencia en Suiza a los representantes más destacados del panorama literario alemán, así como a los refugiados políticos que se dediquen a una actividad literaria. También se les permitirá trabajar en nuestro país. Por el contrario, se tomarán decisiones contundentes respecto de los autores de poco calado que únicamente hayan venido a Suiza para aprovecharse de la coyuntura. (Geistesarbeiter 13: julio 1934)

Las medidas de protección que se tomaron ante una afluencia de refugiados tan extraordinaria no parecen ni lógicas, ni humanas, pues aunque sí se acogía con satisfacción a aquellos escritores que gozaban ya de reconocimiento en Alemania, la realidad es que en ningún momento se toleró que se expresasen abiertamente sobre la situación política en su país, así como tampoco sobre las terribles consecuencias que ésta tuvo para muchos de ellos. Algunos escritores suizos se resistieron a esta doctrina, pero a todos aquellos que tenían algún interés por la literatura del exilio se les silenció radicalmente. Aun con todo, fueron muy pocos: la triste realidad fue que casi todos los autores del país guardaron las distancias con los escritores exiliados que llegaron a Suiza durante aquellos años. Y es que tampoco la situación era fácil, pues cualquier proyecto de publicación había de ser supervisado necesariamente por la mencionada Asociación de Escritores Suizos y plegarse a su veredicto, el cual, en muchas ocasiones, llegaba incluso a anular la posibilidad de publicar. Es lo que le ocurrió a autores como Rudolf Jakob Humm, Jakob Bührer, Alfred Fankhauser, Hans Mühlestein o Carl Albert Loosli, quienes apoyaron en numerosas ocasiones a los autores en el exilio y, debido a ello, su propia obra se encontró con fuertes reticencias y dificultades dentro de amplios sectores de la sociedad suiza ${ }^{7}$. Las restricciones, no obstante, no se limitaron a los autores, sino que llegaron incluso más lejos, pues, por poner tan sólo un ejemplo, los editores extranjeros hubieron de hacer

7 La obra de muchos de estos autores está empezando ahora a ser analizada como se merece y a situarse en el lugar que siempre debió ocupar dentro de la historia de la literatura suiza. 
frente también a una gran resistencia por parte de los editores suizos que los entendían como competencia desleal dentro de su país y no deseaban, por tanto, el establecimiento de editoriales extranjeras para poder proteger así las suyas propias ${ }^{8}$.

A pesar de lo complejo de la situación, entre el 19 de abril y el 15 de noviembre de ese año, Else consigue vivir en Suiza sin visado. Para ella, Suiza era el mejor de los destinos posibles, pues allí se hablaba alemán, conocía a personas influyentes, había una sinagoga y, al final, logró entablar una estrecha amistad con algunos de los emigrantes residentes en el país, entre otros con Klaus Mann, quien poco tiempo después le posibilitaría la publicación de algunos de sus textos. El viaje desde Berlín le había resultado muy desagradable y, al llegar a Zúrich, se dirigió al hospicio del Augustinerhof, desde donde envió una postal a su amiga Hulda Pankok, en la que le escribe que se ha visto obligada a dormir en un banco en la calle durante cinco noches, y que tiene las manos heladas y llenas de cortes. Nunca se ha podido saber por qué Else pasó esas noches junto al lago; la mayoría de sus biógrafos se inclinan por pensar que las condiciones en que la escritora llegó a Suiza fueron tan desfavorables, tanto física como psíquicamente, que la llevaban a salir del albergue por la noche, sin que luego se sintiera capaz de regresar.

Dadas sus dificultades económicas, la Asociación para la Cultura Judía (Jüdischer Kulturverband), al enterarse de que estaba en Suiza, decidió pagarle el alojamiento hasta que el abogado Emil Raas (1910-1973), a quien conocía de tiempos mejores en el país, la sacó de allí y se la llevó a Berna, donde le organizó veladas de lecturas. Else se conforma hasta con los honorarios más bajos por su trabajo, pero gracias a ello, poco a poco, vuelve pronto a publicar colaboraciones en antologías, periódicos y revistas, hace lecturas públicas en librerías, en círculos de emigrantes, en casas de estudiantes, y también algunas otras en la radio. Sin embargo, dos conferencias en la radio de Berna que le había ofrecido Carl Seelig se llevaron a cabo sin permiso policial y le conllevaron una multa de 27,10 francos. En noviembre de ese mismo año, dada su condición de judía, los servicios de inmigración le prohíben ejercer su profesión de poetisa, único requisito que se había establecido como de cumplimiento necesario para otorgarle el permiso de residencia. A partir de ese instante, Else no tiene derecho ya a ejercer ninguna actividad literaria en público y tampoco a publicar en la prensa ni en ninguna casa editorial. Para controlarla, la policía de Zúrich la hace vigilar por unos detectives, que le exigen los nombres de quienes le financian los viajes y la sostienen económicamente en el país. Ante estos mismos detectives, Else se queja de que sus libros hayan sido prohibidos en Alemania. Tales declaraciones llevan a la policía a concluir que padece una enfermedad paranoica y a someterla, por tanto, a una vigilancia mucho más férrea. El primer verano de su exilio en Suiza, a fin de poder solicitar la residencia en Zúrich, se trasladó durante dos meses a Locarno, donde pagaba por una habitación tres francos al día, una cantidad mucho menor que en la ciudad. La estancia en el sur se presentaba prometedora, pero el ruido de la calle y los cuarenta grados de temperatura en la habitación del hotel le resultaron insoportables. A pesar de todo, intentó continuar

${ }^{8}$ En este sentido, véase el estudio de Walser (1972, 2: 125 y ss.). 
trabajando y en agosto realizó una lectura en el teatro de San Materno de Ascona, a la que seguiría otra poco después.

En marzo de 1934, año en que comienza a trabajar en su libro Das Hebräerland (La tierra de los hebreos), Else viaja a Alejandría, animada por su amiga Margret Pilavachi, que se había hecho ya un nombre y tenía muchas amistades en círculos políticos e intelectuales de la ciudad egipcia. Tras un viaje en un vapor de lujo, Else llega a puerto para encontrarse con que lo que Margret le había prometido no coincidía prácticamente en nada con la realidad. Lo cierto es que, desde que los padres del lugarteniente de Hitler, Erich Rommel, se hubieron asentado en la ciudad, la situación había cambiado sustancialmente para los judíos y Margret no se atrevía ya a desarrollar la actividad literaria y artística que había previsto para la poetisa. De nuevo volvía a sentirse como una mendiga, dependiendo siempre de terceros, de modo que, dada la cercanía, decidió poner rumbo a Palestina, donde pasó un total de ocho semanas agotadoras y donde volvió a encontrar a un buen número de amigos de Berlín. Su periplo por el país durante este viaje lo describe en Das Hebräerland, una obra que, con sus meditaciones y sus extractos autobiográficos, supone en realidad la suma de su vida.

El 30 de mayo, Else regresa desde Haifa a la ciudad de Trieste. Desde allí atravesó Yugoslavia para dirigirse a Viena, donde pasó una semana en casa de su amiga Julia Wassermann, la primera esposa del también escritor Jakob Wassermann. A su llegada a Zúrich se aloja esta vez en el hotel Glockenhof, pero no se presenta a las autoridades de inmigración hasta el mes de octubre, hecho que le conllevó una multa de siete francos y una nota en su acta en la que se ponía de manifiesto que en ningún momento se había requerido su presencia en la ciudad. El 30 de octubre se le deniega por vez primera el permiso de residencia, negativa que fue desestimada gracias a la intervención del Dr. Steinmarder, un abogado amigo de Else. Pero el permiso expiraba el 30 de junio, con lo cual decide pasar el verano en Ascona. Allí se establece en casa de la familia Berger Signorelli, dueña de una pastelería situada en la vía Borgo, frente al café Verbano. El alojamiento fue financiado en esta ocasión por dos directores de unos grandes almacenes, que le enviaban cien francos mensuales a cambio de uno de sus dibujos al mes respectivamente. De los cien francos, cincuenta eran para el alquiler, el resto para comer y para comprar el material que necesitaba para sus dibujos. Else no regresó a Zúrich hasta pasados catorce meses, pero todos ellos no fueron para la escritora sino un exilio en el exilio: su frágil salud no encontró en esta localidad repleta de empinadas calles el destino más adecuado, y, de hecho, fue allí donde por vez primera Else sufrió una leve angina de pecho el 17 de marzo de 1936, durante el segundo verano que pasó en Ascona. Además de eso, padeció mucho por el frío del invierno y por el ruido de la gente; de lo único que se sentía capaz era de dibujar en los muchos ratos que pasaba en el café Verbano, adonde acudía para resguardarse del frío de su habitación, y donde era conocida por todos. Sin embargo, a pesar de sus escasas posibilidades, Else no dejó de prestar ayuda en todo momento a quien la necesitaba; como al estudiante de Medicina David Frankfurter, que el 5 de febrero había disparado en Davos contra el dirigente local del partido nacionalsocialista, o a un desertor alemán que había introducido en Suiza a un conocido de manera ilegal. A pesar de estas actividades su producción se 
resintió, pues el paisaje del Tesino no le inspiraba y también echaba en falta gente con la que poder conversar sobre cuestiones de actualidad, sobre política. Un posible espionaje retraía a cualquiera de entablar conversaciones al respecto.

Esta situación tan poco alentadora, este constante ir y venir de un lado a otro, se mantendrá hasta diciembre de 1938, fecha en que se le negará definitivamente la posibilidad de solicitar asilo. Durante todo este largo periodo de tiempo tendrá lugar una lucha incesante con las autoridades suizas por conseguir tanto el permiso de residencia como el de trabajo. Sujeta a tales condiciones, se ve obligada a demandar la ayuda económica de conocidos, pero, a pesar de que obtiene todo el apoyo de Sylvain Guggenheim, propietario de una fábrica textil, las autoridades se aferran a su situación de extranjera sin recursos económicos como motivo fundamental para responder con una negativa a todas sus solicitudes. Ni siquiera puede regalar sus dibujos, pues tal hecho es considerado igualmente como una actividad laboral. A Guggenheim le escribe en 1934: "Estoy desesperada de la vida, admiro a los vagabundos porque tienen el coraje de ir de país en país, a pie" día a las expectativas de Else; sus pretensiones no eran atendidas, y ni siquiera la recomendación positiva de la Asociación de Escritores Suizos consiguió que le concediesen la residencia solicitada.

En junio de 1938 la policía de inmigración trata de expulsar definitivamente a la autora: "Suiza es demasiado pequeña para vender sus libros. El resto de regiones germanófonas le están vetadas; más tarde o más temprano acabará completamente a cargo de la caridad pública" 10 .

La organización judía de la ciudad decide hacerse cargo de ella, evitando así la expulsión, pero el 14 de julio de ese mismo año la Gestapo ordena que Else sea privada de la nacionalidad alemana:

La emigrante judía Else Lasker, de soltera Schüler, divorciada de Lewin, tiene la nacionalidad alemana. Era el ejemplo típico de "mujer emancipada" en la Alemania de posguerra. A través de discursos y de otros escritos trató de honrar las virtudes morales e intelectuales de la mujer alemana. Tras la toma del poder, se marchó a Zúrich, donde ha manifestado su aversión a Alemania difundiendo mentiras infames. Ha seguido escribiendo y publicando artículos en el periódico Pariser Tageblatt, conocido por su visión antialemana. También ha publicado escritos en la editorial Oprecht de Zúrich, a pesar de que el conjunto de su producción está en la lista de escritos peligrosos e indeseables. Por consiguiente, ordeno la desnacionalización de la judía Else Lasker [...]. Firmado: Keller. ${ }^{11}$

Else se siente abandonada, sola y desesperada una vez más. Su situación no puede ser más desalentadora. El dilema al que ha de enfrentarse es grande: en suelo suizo es tolerada en tanto que refugiada, pero no puede ejercer su derecho a ganarse la vida con su trabajo literario y está, además, amenazada de expulsión. A pesar

${ }^{9}$ La carta está fechada el 11 de marzo de 1934 (cfr. Ott 1995: 244).

10 Carta del 17 de mayo de 1938 de la Policía de Inmigración a la Policía cantonal, citada según Ott (1995: 297).

11 Carta de la Gestapo al Reichsführer de las SS y jefe de la Policía alemana en el Ministerio del Reich en Berlín fechada el 14 de mayo de 1938 (cfr. Ott 1995: 298). 
de ello, encuentra una vez más en su propio mundo de ficción las fuerzas para seguir viviendo y escribiendo, y gracias a él consigue superar todas las pruebas materiales y existenciales. No se trata de una nueva huida a un mundo imaginario, a una emigración interior, sino del enfrentamiento con la realidad del exilio, lo que la lleva a componer poemas que publica ahora en la revista Die Sammlung, editada mensualmente en Amsterdam por Klaus Mann, con el apoyo de André Gide, Aldous Huxley y Heinrich Mann.

Resignada ante el hecho de que la oficina de inmigración no le va a prolongar el derecho de asilo, Else proyecta un tercer viaje a Palestina, y con esta idea en mente escribe a Emil Raas el 12 de diciembre de 1938: "Estoy contenta de volver a Jerusalén. Sí, ya no puedo esperar más. No tengo nada que perder, pero Suiza no sabe quién mora dentro de sus montañas. Lo digo en serio. Estoy destrozada de tanta soledad interior" (apud Wüthrich 2007: 44).

El 31 de diciembre de ese mismo año la cámara literaria del Reich establece la lista de escritores cuyas obras serán prohibidas. Todos los libros de Else LaskerSchüler forman parte de ella.

En la primavera de 1939, durante la época de mayor soledad, Else comienza a escribir un diario: Tagebuchzeilen aus Zürich (Notas de un diario de Zúrich). Este diario nunca llegó a publicarse; se encuentra en el archivo de la autora en Jerusalén y contiene treinta y dos páginas mecanografiadas en las que Else acusa a sus conciudadanos cristianos de haber aceptado sin ninguna resistencia la expulsión de los judíos de Alemania. Es el único testimonio de la autora en el que reflexiona y opina sobre la historia contemporánea. Al contrario de lo que ocurre en el resto de sus textos, donde todas sus ideas están escondidas tras metáforas poéticas, casi idealizadas, la autora da voz aquí a sus reflexiones y pensamientos sobre el momento presente de una forma enormemente realista, hablando de la vida cotidiana de un refugiado en Suiza, de la tristeza de los cafés, así como de la espera de un milagro que no llegará jamás. A pesar de que en Suiza el abogado Emil Raas y su amigo Sylvain Guggenheim habían garantizado durante todo el tiempo allí pasado la estabilidad económica de la autora, sin saber, por cierto, que una buena parte del dinero que le entregaban lo utilizaba para pagar el alquiler de su casa en Berlín, lo cierto es que, durante casi siete años, Else no había sido capaz de encontrar un refugio duradero y tampoco el éxito literario que le hubiera permitido vivir dignamente sin tener que mendigar entre personas a las que ella estimaba sobremanera. Todas las tentativas de solicitar amparo acudiendo a sus amigos y a sus influencias fracasaron: en marzo de 1939 se vio obligada a abandonar de nuevo Suiza. Desde allí puso rumbo a Palestina $^{12}$, donde pensaba que podría encontrar definitivamente la utopía descrita en sus textos. Pero la situación no era fácil, pues se encontraba ahora en la típica situación en la que se encuentra todo exiliado: debía marcharse de Suiza, pero no podía entrar en Palestina sin más, pues los ingleses no le permitirían la entrada hasta que hubie-

${ }^{12}$ La Agrupación trató de apoyar la solicitud diciendo que "seguramente se trataba tan sólo de un pequeño grupo el que sigue interesándose aún hoy por la producción artística de la poetisa", y precisamente la mención de este "pequeño grupo" fue lo que incrementó los temores de la policía federal (cfr. Schweizerischer Schriftstellerverband 1987: 141). 
ra depositado en Suiza una fianza de sesenta francos, que, naturalmente, no tenía y que, finalmente, y tras muchos intentos en vano en el consulado, hubo de depositar Sylvain Guggenheim. El visado llegó el 24 de febrero. El 4 de abril arribó a Tel-Aviv completamente agotada. Durante los últimos años su salud se había resquebrajado notablemente.

Al ver la tierra prometida, la imagen de desesperación que albergaba en su interior se convirtió en una esperanza reencontrada; al principio trató de mantener allí el mismo estilo de vida que en Alemania o en Suiza, pero sus tentativas no resultaron más que en una continuación de su vida errante. Allí no existía la vida bohemia de Berlín, y tampoco tenía trabajo. Además, las posibilidades de publicar alguna obra en Palestina eran aún menores que en Suiza, dado el odio reinante hacia la lengua alemana. Por otro lado, la situación en Palestina no era la misma que había visto la vez anterior, pues ahora había un exceso de agitación política que no le agradaba. Durante los primeros meses que pasó en el hotel Vienna, Else no deshizo siquiera las maletas, esperanzada siempre con la idea de ese pronto regreso que albergaba en su mente, y durmió durante muchas noches en una mecedora. El sentimiento de soledad fue acentuándose allí aún más que en Suiza, dando lugar en su subconsciente a un miedo constante, que le provocó varias crisis de pánico y que la condujo de nuevo a su mundo particular, al mundo interior de sus personajes literarios.

No obstante, que Else pensaba regresar a Zúrich lo demuestra el hecho de que, al marcharse, dejó a Heinrich Münch, el propietario del hotel en el que se alojaba, cinco maletas llenas, una clara señal de que no consideraba su marcha como definitiva. Münch le prometió guardarlas, pero al final las maletas desaparecieron. A todas ellas Else hacía referencia en una libreta conservada en el legado de la autora en Jerusalén. Cuatro de ellas, las más grandes, aparecieron trece años después de su muerte en los sótanos del Kunsthaus de Zúrich. La quinta maleta, más pequeña que las otras y de la que nadie parecía saber nada, y que contenía correcciones de pruebas de algunas obras, así como diversos textos inéditos, apareció en 1995 en el sótano de la editorial Oprecht, poco antes de la exposición sobre la autora que, bajo el título "Sieh in mein verwandertes Gesicht" ("Mira mi rostro transformado"), se celebró en la Kunsthalle Barmen de Wuppertal del 9 de abril al 28 de mayo de ese mismo año $0^{13}$.

A la vista, pues, de todo lo que la autora se vio obligada a vivir en Suiza, no deja de resultar extraño que, después de cada viaje, siguiera intentando una y otra vez regresar a la Confederación, a pesar de que el país nunca la acogió con agrado ni llegó a tener en él las condiciones de vida tan positivas que ella esperaba. Pero, curiosamente, Else prefería dejar que la persiguiera la policía suiza antes que tratar de instalarse definitivamente en Palestina, y ello porque, a pesar de haber idealizado también este país como lugar en el que hacer verdaderamente real su ideal de convivencia pacífica, Else no había pensado nunca seriamente en establecerse allí

13 De forma completamente inesperada, la maleta de cartón se convirtió en el eje en torno al que giró toda la exposición. Acerca de la historia que suscitó la maleta véase Ziegler (2007: 231-249). 
para siempre: lo que deseaba en el fondo era poder volver a Alemania ${ }^{14}$. Con esta sola idea en su mente, Else había decidido abandonar Suiza una vez más con la intención de poder regresar después legalmente y trasladarse desde allí a Berlín. Lo que Else no sabe es que ya no regresará jamás: la invasión de Polonia por las tropas alemanas el 1 de septiembre de ese mismo año anula toda esperanza de un posible regreso, y será allí, en Palestina, donde recibirá la notificación de la policía suiza con la prohibición de retorno.

Después de la II Guerra Mundial, Else Lasker-Schüler cayó en el olvido. A diferencia de otros autores como Bertolt Brecht, su obra permaneció largo tiempo sin leerse ni editarse en Alemania. Pero curiosamente, fue justo en Suiza, en el país que ella tanto amó y que no supo corresponderla, donde tuvo lugar su redescubrimiento, primero a través de su círculo de amigos, entre los que se encontraba el actor y director teatral Ernst Ginsberg, quien poco a poco fue editando sus obras y llevando a cabo lecturas públicas de la misma, y luego a través del famoso historiador de la literatura Walter Muschg, quien, en un amplio estudio sobre el Expresionismo, situó su obra al lado de la de autores de la talla de Hugo von Hofmannsthal, Karl Kraus, Franz Kafka, Georg Trakl y Bertolt Brecht, testimoniando de manera ejemplar que Else Lasker-Schüler era, junto con Anette von Droste-Hülshoff, la poetisa más grande de las letras alemanas ${ }^{15}$.

A lo largo de los años siguientes la obra de Lasker-Schüler experimentó una rápida recuperación y volvió a reeditarse, con la consiguiente revalorización de muchas de sus obras por parte de autores, lectores y críticos. Tal vez uno de los comentarios más llamativos sea el de Friedrich Dürrenmatt, el gran dramaturgo y narrador suizo, y que también experimentó en el campo de la lírica, al hilo de una reflexión sobre otro gran poeta, Rainer Maria Rilke:

Ella veía todas las cosas como si las viera por primera vez [...]. Él [Rilke] era mucho más seguro, tenía más nivel que ella, que era como una montañita mucho más audaz que él, que era de naturaleza volcánica, con escarpados precipicios y alturas mucho mayores. (Dürrenmatt 1996: 251-254)

A lo largo de toda su vida, Else había tratado de acercarse a las personas, fueran de la condición que fueran, sin conseguirlo. Pero, a pesar de haber vivido imbuida en un mundo particular, en su propio mundo interno, pocas son las personas capaces de ahondar en la esencia humana con tanta profundidad como llegó a hacerlo esta gran poetisa alemana.

14 Durante todo el tiempo que pasó en Suiza, Else mantuvo en alquiler su casa de Berlín; su nostalgia de Alemania era enorme y el hecho de mantener su casa le parecía la única posibilidad de volver algún día a la ciudad. Su círculo de amigos de Berlín nunca la olvidó y mantuvo siempre una viva correspondencia con ella. Una de sus amigas, Hedwig Grieger, estuvo ahorrando durante largo tiempo para poder visitarla en Zúrich, pero una vez conseguido el dinero y realizado el viaje, se encontró a su llegada a la ciudad suiza con que Else había tenido que marcharse a Palestina para poder solicitar un nuevo visado.

15 Se trata del estudio de 1961 titulado Von Trakl zu Brecht. Dichter des Expressionismus (Muschg 1961: 115-148). 
Else Lasker-Schüler falleció a las 7 de la mañana del 22 de enero de 1945 en el hospital Hadassa de Jerusalén, a consecuencia de un infarto de miocardio provocado por una angina de pecho. La última palabra que pronunció fue "mamá".

\section{BIBLIOGRAFÍA}

BAUSCHINGER, Sigrid (2004): Else Lasker-Schüler. Biographie. Göttingen: Wallstein.

BUNDESAMT FÜR FLÜCHTLINGE, MEDIEN \& KOMMUNIKATION (ed.) (2003): Prominente Flüchtlinge im Schweizer Exil. Berna: Bundesamt für Flüchtlinge, Medien \& Kommunikation.

CORINO, Karl (1981): Autoren im Exil. Frankfurt: Fischer.

DÜRRENMATT, Friedrich (1966): Theaterschriften und Reden. Zúrich: Diogenes.

EICHMANN-LEUTENEGGER, Beatrice (1994): “'Gejagt, gehetzt, verfolgt, verbannt...'. Emigrantinnen des 20. Jahrhunderts in der Schweiz", en Und schrieb und schrieb wie ein Tiger aus dem Busch, Elisabeth Ryter et al. (eds.), pp. 206-224. Zúrich: Limmat.

FRISCH, Shelley (ed.) (1987): Women in Exile. Special issue of The Germanic Review, 57.3, pp. 107-157.

FRÜHWALD, Wolfgang; \& SCHIEDER, Wolfgang (eds.) (1981): Leben im Exil: Probleme der Integration deutscher Flüchtlinge im Ausland 1933-1945. Hamburgo: Hoffmann und Campe.

GOLL, Claire (1999): Ich verzeihe keinem. Eine literarische Chronique scandaleuse unserer Zeit. Múnich: Knaur.

JAHN, Hajo (ed.) (2007): „Wo soll ich hin?“ Zuflucht Zürich - Fluchtpunkt Poesie. Wuppertal: Peter Hammer.

KOSCH, Arlette (2002): Literarisches Zürich. Jena: Fritsch.

LEGREID, Sissel (2006): “'Das schwarze Auge der Mitternacht'. Topographien des Exils oder das Unheimliche in der Lyrik von Else Lasker-Schüler". Else Lasker-Schüler-Jahrbuch 3, pp. 1-25.

LIXL-PURCELL, Andreas (ed.) (1988): Women of Exile. German-Jewish Autobiographies since 1933. Nueva York: Greenwood Press.

MITTENZWEI, Werner (1981): Exil in der Schweiz. Leipzig: Reclam.

MUSCHG, Walter (1961): Von Trakl zu Brecht. Dichter des Expressionismus. Múnich: Piper. OTT, Ulrich (1995): “Else Lasker-Schüler. 1869-1945”. Marbacher Magazin 71, pp. 244.

SCHWEIZERISCHER SCHRIFTSTELLERVERBAND (ed.) (1987): Literatur geht nach Brot. Die Geschichte des Schweizerischen Schriftsteller-Verbandes SSV. Aarau / Frankfurt.

TUDYKA, Caroline (2001): L'exil d'Else Lasker-Schüler (1869-1945). París: L'Harmattan.

VON MATT, Peter (2003): "Die Macht an der Grenze", en Prominente Flüchtlinge im Schweizer Exil. Bundesamt für Flüchtlinge, Medien \& Kommunikation (ed.), p. 7. Berna: Bundesamt für Flüchtlinge, Medien \& Kommunikation.

WALSER, Hans-Albert (1972): Asylpraxis udn Lebensbedingungen in Europa, vol. 2. Darmstadt: Luchterhand.

WÜTHRICH, Werner (2007): "Ich habe grauenhafte Wochen hinter mir", en Wo soll ich hin? Zuflucht Zürich - Fluchtpunkt Poesie. Else-Lasker-Schüler-Almanach, Hajo Jahn (ed.). Wuppertal: Peter Hammer.

ZIEGLER, Ernst-Andreas (2007): "Die Geschichte vom letzten Koffer", en JAHN 2007: 231-249. 